\title{
Design and development of three levels universal electric vehicle charger based on integration of VOC and SPWM techniques
}

\begin{abstract}
In order to successfully launch Electric vehicles (EVs) over the actual world, EVs battery chargers have a crucial role to predict the charging time. This work presents the design process of a universal EV charger, The proposed charger is able of providing a controllable and constant charging voltage for a various EVs, which is composed of three levels of charging, $650 \mathrm{~V} / 100 \mathrm{~A}$ DC for bus or lorry, single-phase $120 \mathrm{~V} / 16 \mathrm{~A}$ AC for motorcycle, and three-phase $240 \mathrm{~V} / 60 \mathrm{~A}$ for saloon car battery charging. The output voltage ranges are $40 \mathrm{~V}-$ $60 \mathrm{~V}, 400 \mathrm{~V}-500 \mathrm{~V}$, or $500 \mathrm{~V}-600 \mathrm{~V}$. The power system of this work consists of two converters; First one, is for the three-phase pulse-width modulated (PWM) of a bridge rectifier with an output of $850 \mathrm{~V} \mathrm{DC}$ unregulated voltage, while the second converter is for the three-phase DC-DC converter. To satisfy the voltage control and the isolation between Grid To Vehicle (G2V), a three-phase transformer has been exploited within the DC/DC converter. The primary output circuit achieved the charge levels one and two, while the whole circuit output can charge level three or the DC charge. For efficient and secure battery charging, voltageoriented control (VOC) technique is proposed. The unity power factor for the PWM-based rectifier and SPWM are designed and evaluated using MATLAB/Simulink block sets. The total harmonic distortion (THD) for the input current is less than 5\%, while the overall simulation-based efficiency is more than $97 \%$. A prototype and simulation results validate that the proposed EV charger is robust, accurate, and applicable.
\end{abstract}

Keyword: Electric vehicle charger; Off board charging; On-board; Voltage-oriented control 